\title{
Relações planta-animal em ambiente pastoril heterogêneo: padrões de desfolhação e seleção de dietas ${ }^{1}$
}

\section{Edna Nunes Gonçalves ${ }^{2}$, Paulo César de Faccio Carvalho ${ }^{3}$, Carlos Eduardo Gonçalves da Silva $^{4}$, Davi Teixeira dos Santos ${ }^{2}$, José Augusto Queirolo Díaz ${ }^{4}$, Carolina Baggio², Carlos Nabinger ${ }^{3}$}

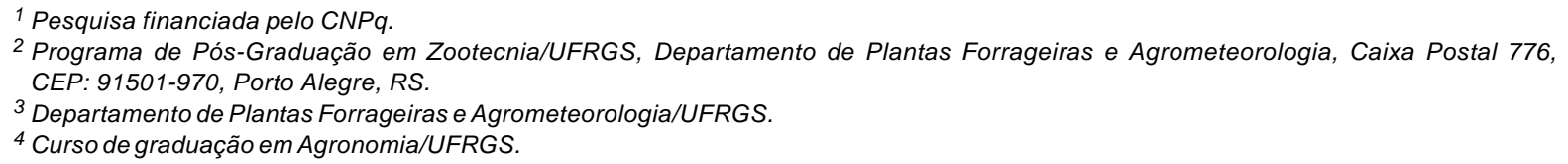

RESUMO - Um experimento foi conduzido para avaliar o efeito das alturas de manejo do pasto (4, 8, 12 e $16 \mathrm{~cm})$ no padrão de desfolhação de uma pastagem nativa e na seletividade de bezerras e ovelhas em testes de pastejo de 45 minutos. $\mathrm{O}$ delineamento estatístico utilizado foi o inteiramente casualizado, com quatro alturas de manejo e duas repetições no tempo e no espaço. Quarenta perfilhos marcados por unidade experimental foram usados para determinar o número e comprimento de lâminas foliares. Para caracterizar o padrão de desfolhação do pasto, determinaram-se as probabilidade de desfolhação e os índices de seletividade passiva e ativa. Houve correlação positiva da altura do pasto com a massa de forragem, e negativa com a densidade de forragem. A partir de $4 \mathrm{~cm}$, a participação de lâminas foliares foi quase que exclusiva, o que indica condições potenciais para a ingestão de forragem pelos animais. A probabilidade de desfolhação diminuiu com o aumento da altura, como conseqüência da menor relação lotação animal/forragem disponível. Os índices de seletividade passiva (ISP) e ativa (ISA) foram afetados negativamente pela altura do pasto. O índice de seletividade passiva não diferiu entre bezerras e ovelhas e, após $6,7 \mathrm{~cm}$, o consumo de lâminas em expansão foi menor que o de lâminas expandidas, no entanto, não significou que os animais deixaram de selecionar as lâminas em expansão, pois o índice de seletividade ativa permaneceu, em ambas as espécies animais, acima do valor de referência 1. A estrutura do campo nativo afeta o padrão de desfolhação e a oportunidade de pastejo de bezerras e ovelhas, pois o aumento da altura representa menor facilidade de apreensão das lâminas foliares, uma vez que há menor densidade de lâminas foliares nos estratos superiores, porém os animais buscam sempre selecionar folhas mais jovens.

Palavras-chave: bezerras, estrutura do pasto, ovelhas, pastagem nativa, seletividade

\section{Plant-animal relationships in pastoral heterogeneous environments: defoliation and selectivity patterns}

ABSTRACT - The experiment was conduced to evaluate the effect of different native pasture structures, represented by four sward heights $(4,812$ and $16 \mathrm{~cm})$ on defoliation and selectivity patterns of calves and ewes, in 45 -minute grazing tests. A completely randomized design with four treatments and two replicates in time and space were used. Sward structure was characterized by sward height, herbage mass, leaf blade mass, herbage bulk density, leaf blade bulk density, and number and length of fully-emerged and emerging leaves. Forty tillers were marked in each experimental unit to determine the number and length of leaf blade. Defoliation and selectivity patterns were evaluated by defoliation probability and by passive selectively (PS) and active selectively (AS) indexes. A positive correlation between sward height and herbage mass, and negative between sward height and herbage bulk density were observed. Above $4 \mathrm{~cm}$, leaf blade was almost exclusive, meaning optimal conditions for herbage intake by the animals. A reduction in the defoliation probability was observed with increasing sward height due to a lower stocking rate/available forage relationship. PS and AS were negatively affected by sward height. PS did not differ between calves and ewes, and above $6.7 \mathrm{~cm}$, animals consumed less emerging leaf blade in relation to fully-emerged leaf blade. However, it did not mean that animals fail to select leaf blade, since AS remained above reference value 1 for both animal species. Ewes differed from calves in terms of AS. The increase in sward height affects the opportunity of animals to find emerging leaf blade, however, they selected younger leaf blade in the attempt to obtain a better food quality. Ewes selected emerging leaf blade more effectively than calves.

Key Words: calves, ewes, native pasture, selectively, sward structure 


\section{Introdução}

No ecossistema pastoril, a compreensão dos efeitos da estrutura do pasto sobre o processo de desfolhação dos animais é necessária para melhor exploração, tanto da produtividade dos animais quanto da vegetação. Busca-se, desta forma, fundamentar ações de manejo do pasto que possam ser racionais e sustentáveis.

A estrutura do pasto pode ser descrita sob os planos vertical e horizontal e seu detalhamento é minucioso, primordial para o entendimento das relações entre as plantas forrageiras e os animais, pois, em condições de pastejo, o animal a reconhece e, dentro da variabilidade disponível, faz suas escolhas alimentares por meio da desfolhação (Marriot \& Carrère, 1998).

A disponibilidade de forragem, diretamente relacionada à densidade de animais, determina a probabilidade de desfolhação de cada componente da pastagem, uma vez que, quando lhes é permitido, os animais utilizam sua habilidade seletiva com o objetivo de aumentar a qualidade de sua dieta. Essas escolhas pelos animais podem ser diretamente influenciadas por características relacionadas à apreensibilidade da forragem, um indicador para o animal do grau de facilidade da ação do bocado (Carvalho et al., 2001). Essas características incluem aspectos estruturais do pasto, como a acessibilidade e a densidade volumétrica da forragem, a fibrosidade das folhas, a disposição espacial dos tecidos vegetais preferidos, a presença de barreiras à desfolhação, como bainhas e colmos, e o teor de matéria seca (Silva, 2004).

A seletividade está relacionada à heterogeneidade e à estrutura do pasto, pois, para consumir determinada fração forrageira, rejeitando outra, o animal deve ser capaz de diferenciá-la e colhê-la. Uma vez que a heterogeneidade pode ser percebida pelo animal, o processo de seleção de dietas pode ocorrer em diversos níveis: em sítios de alimentação dentro de uma pastagem; em espécies dentro de um sítio; ou em órgãos dentro de uma planta. Esse nível de seleção depende não somente das características do pasto, mas também da capacidade de seleção do próprio animal (Galli et al., 1996). A probabilidade de desfolhação de folhas individuais é maior em folhas jovens (Lemaire \& Agnusdei, 1999), por sua maior qualidade nutricional (Briske \& Richards, 1995). Silva (2004) determinou dois índices de seletividade - passivo e ativo - que ajudam a esclarecer como os animais podem selecionar partes de uma planta durante o processo de pastejo. $O$ índice de seletividade passiva indica a preferência dos animais, pois, conforme aumenta a altura do pasto, as lâminas em expansão podem se tornar menos acessíveis em relação às expandidas e, portanto, são menos consumidas. $\mathrm{O}$ índice de seletividade ativa, no entanto, como inclui o número de folhas consumidas em relação ao total de folhas em expansão e expandidas, indica até que ponto a pouca acessibilidade das folhas em expansão pode prejudicar sua seletividade.

O objetivo neste trabalho foi avaliar o efeito das alturas de manejo do pasto em uma pastagem nativa sobre o padrão de desfolhação e a seletividade de bezerras e ovelhas em pastejo.

\section{Material e Métodos}

A área experimental, formada por uma pastagem natural, estava situada na Depressão Central do Rio Grande do Sul, no município de Eldorado do Sul, pertencente à Estação Experimental Agronômica da UFGRS. O tipo de solo predominante pertence à classe taxonômica Plintossolo, caracterizada por solos mediamente profundos, mal drenados, de textura franco-arenosa, ácidos, com baixos teores de matéria orgânica, de fósforo e de saturação de bases (EMBRAPA, 1999). O clima da região é do tipo Cfa, subtropical úmido com verão quente, segundo classificação de Köppen. As principais espécies encontradas na área experimental de todas as alturas de manejo foram Paspalum notatum e Axonopus affinis, com cobertura de 1/4 a 1/2 da superfície, e, Desmodium incanum e Paspalum plicatulum, com cobertura escassa ou cobrindo entre 1/10 e 1/4 da superfície, segundo classificação de BraunBlanquet (1979).

As alturas do pasto corresponderam a 4,8,12 e $16 \mathrm{~cm}$, com duas repetições de piquete e duas repetições no tempo, totalizando 16 testes de pastejo para cada espécie animal (ovinos e bovinos), realizados no período de 24/10/2006 a 4/12/2006. A área de cada um dos oito piquetes correspondeu a $187 \mathrm{~m}^{2}$. Para a realização dos testes de pastejo, foram utilizadas quatro bezerras de raça indefinida, com 12 meses de idade, pesando $160 \mathrm{~kg}$ de PV $( \pm 4 \mathrm{~kg})$ e com largura da arcada dentária medindo $60 \mathrm{~mm}( \pm 2 \mathrm{~mm})$, e quatro ovelhas da raça Suffolk, com 36 meses de idade, pesando $62 \mathrm{~kg}$ de PV $( \pm 4 \mathrm{~kg})$ e com largura da arcada dentária medindo $35 \mathrm{~mm}$ ( $\pm 2 \mathrm{~mm}$ ). Visando obtenção do efeito de grupo, descrito por Arnold (1987), foram adicionadas mais duas bezerras (segundo Rind \& Phillips, 1999) e quatro ovelhas (segundo Penning et al., 1993), no período de seus respectivos testes de pastejo, apenas para compor o lote. Em cada dia de avaliação, foram feitos os testes de pastejo para determinação das variáveis que compõem o processo de desfolhação e caracterização da estrutura do pasto na unidade experi- 
mental avaliada. Desta forma, na primeira fase, os testes de pastejo foram realizados com as bezerras nas quatro alturas de manejo e suas respectivas repetições ( 8 dias $=4$ tratamentos $\times 2$ repetições) e, na segunda fase, foram destinados mais oito dias às avaliações com as ovelhas. As duas fases foram repetidas para ambas as espécies animais com a finalidade de obter duas repetições no tempo, totalizando 32 dias de avaliação.

A estrutura do pasto foi previamente moldada ao longo de três anos por meio de pastejo controlado, uma vez que, não somente as alturas absolutas deveriam ser objeto de estudo, mas também suas respectivas estruturas, condição que seria atingida somente com a manutenção das alturas de pastejo por prolongado período de tempo. Para medição da altura do pasto, utilizou-se um bastão graduado ( $s w a r d$ stick), cujo marcador corre por uma "régua" até tocar a primeira lâmina foliar, procedendo-se então à leitura da altura (Barthram, 1985). As medições foram realizadas de forma aleatória, totalizando 50 pontos em cada unidade experimental (piquete). Para garantir que o tempo de permanência dos animais no piquete não afetasse a estrutura do pasto, foram realizadas medidas antes e após os testes de pastejo, considerando válidos apenas aqueles testes com variação máxima de $5 \%$ em relação à altura inicial.

A quantificação da massa de forragem foi realizada em duas amostras do pasto, coletadas previamente aos testes de pastejo, estratificadas a cada $4 \mathrm{~cm}$ de altura, utilizando-se um equipamento denominado estratificador, composto de uma estrutura retangular metálica, de área de $0,1230 \mathrm{~m}^{2}$ $(30 \times 41 \mathrm{~cm})$ e uma régua graduada por onde o retângulo deslizava até as alturas desejadas. A forragem, em cada estrato, foi cortada com tesoura partindo-se da maior altura até o nível do solo. As amostras estratificadas, depois de cortadas, foram separadas em lâminas foliares, colmos e material senescente e, em seguida, foram colocadas em estufa de circulação forçada de ar a $65^{\circ} \mathrm{C}$ até peso constante. Posteriormente, foram pesadas para obtenção da massa seca de cada componente, expressa em $\mathrm{kg}$ de MS/ha. O quociente entre as massas de forragem e de lâminas foliares pela altura do pasto compôs o cálculo de suas respectivas densidades volumétricas, expressas em $\mathrm{mg}$ de $\mathrm{MS} / \mathrm{cm}^{3}$.

A oferta de forragem instantânea ( $\mathrm{kg}$ de MS/kg de PM) foi obtida pelo quociente entre a massa de forragem instantânea e o peso metabólico (PM) de cada espécie animal. O peso metabólico, por sua vez, foi determinado pela equação $\mathrm{PM}=(\text { peso vivo })^{0,75}$ e definido com detalhes por OwenSmith (1999).

O protocolo experimental previa a realização de um teste de pastejo por dia, feito em duas etapas, com início sempre às 14 h e término às $17 \mathrm{~h}$. Na etapa 1, após jejum de sólidos e líquidos por 5 horas, os quatro animais experimentais foram divididos em dois grupos. O primeiro grupo (animais A e B) foi levado à área experimental junto com os animais acompanhantes, por um período de 45 minutos, enquanto o segundo grupo (animais C e D) permaneceu, pelo mesmo período, em uma área não vegetada (área de espera), impossibilitados de consumir água e alimentos sólidos.

Na etapa 2, os animais A e B, que anteriormente foram avaliados nos testes de pastejo, passaram para a área de espera, impossibilitados de consumir sólidos e líquidos, e os animais C e D, por sua vez, passaram para os testes de pastejo, repetindo-se os mesmos procedimentos anteriores.

O número e comprimento das lâminas foliares expandidas e em expansão foram determinados em 40 perfilhos marcados, escolhidos de forma aleatória em cada unidade experimental (piquete). Esses perfilhos foram aleatorizados de forma que significassem uma média representativa da principal comunidade (gramíneas) constituinte da pastagem natural em estudo. Quatro transectas foram distribuídas ao longo dos piquetes, de forma a representar toda a superfície disponível para os animais, excetuando-se as proximidades de cerca. Os perfilhos foram marcados utilizando-se fios de telefone coloridos para facilitar a identificação. Para medição do comprimento das lâminas foliares expandidas e em expansão, utilizou-se régua graduada em milímetros. Todas as folhas dos perfilhos marcados foram medidas com régua do nível do solo até o ápice da lâmina foliar, imediatamente antes e após os testes de pastejo. Consideraram-se lâminas completamente expandidas quando a lígula apresentava-se exteriorizada, caso contrário, eram lâminas em expansão.

O padrão de desfolhação do pasto e a seletividade pelos animais foram determinados considerando as seguintes variáveis, obtidas pela medição dos perfilhos marcados:

a) probabilidade de desfolhação $=\frac{N T F C}{N T F}$;

em que $\mathrm{NTFC}=$ número total de folhas consumidas; e NTF = número total de folhas.

b) índice de seletividade passiva $=\frac{N F e \exp C}{N F \exp C}$;

em que NFeexpC = número de folhas em expansão consumidas; e NFexpC = número de folhas expandidas consumidas.

c) índice de seletividade ativa $=\frac{(N F e \exp C \div N T F e \exp )}{(N F \exp C \div N T F \exp )}$; 
em que $\mathrm{NFeexpC}=$ número de folhas em expansão consumidas $;$ NTFeexp $=$ número total de folhas em expansão; $\mathrm{NFexpC}=$ número de folhas expandidas consumidas; $\mathrm{e}$ NTFexp = número total de folhas expandidas.

O delineamento estatístico utilizado foi o inteiramente casualizado, com quatro alturas de manejo e duas repetições no tempo e no espaço. Na avaliação das variáveis repetidas no tempo, utilizou-se o procedimento MIXED e, quando detectadas diferenças, as médias foram comparadas pelo teste $\mathrm{t}$ de Student (PDIFF) utilizando-se nível de significância de $10 \%$ para a avaliação dos resultados. Também foram realizadas regressões até terceira ordem e análises de correlação a partir do pacote estatístico Statiscal Analysis System (SAS, 1996).

\section{Resultados e Discussão}

$\mathrm{Na}$ análise de regressão, as alturas médias reais de pastejo apresentaram resposta linear e significativa $(\mathrm{P}=0,002)$, o que garantiu a independência das variáveis avaliadas (Tabela 1).

A variação máxima pré-estabelecida, de $5 \%$, para a diferença de altura do pasto entre a entrada e a saída dos animais nas unidades experimentais foi obedecida em todas as alturas de manejo, portanto, na média, a estrutura do pasto não foi alterada pelo teste de pastejo.

Os valores de massas de forragem e de lâminas foliares ajustaram-se ao modelo de regressão linear $(\mathrm{P}<0,0001)$, comprovando que, para cada aumento de $1 \mathrm{~cm}$ na altura do pasto (a partir de $4 \mathrm{~cm}$ ), a massa de forragem aumentou $117 \mathrm{~kg}$ de MS/ha $(y=116,77 x+1033,22)$. Esse valor surpreende, pois é muito semelhante ao de massa por unidade de altura (em cm) em misturas de aveia e azevém, $117 \mathrm{~kg}$ de MS/ha (Aguinaga et al., 2006), em milheto (107 kg de MS/ha; Castro, 2002) e em capim-mombaça, $127 \mathrm{~kg}$ de MS/ha (Silva, 2004). Esses resultados sugerem que a ocupação do espaço pelos tecidos vegetais obedeceria a mesma relação massa/volume, o que poderia se constituir interessante linha de investigação sobre a alocação espacial da MS construída, hipótese anteriormente levantada por Carvalho et al. (2001). A massa de lâminas foliares teve aumento de $63 \mathrm{~kg}$ de MS/ha $(y=62,95 x+462,04)$, o que também reflete a relação positiva entre altura do pasto e a disponibilidade de forragem. As densidades de forragem (DF) e de lâminas foliares (DL) também foram mais bem ajustadas por regressões lineares $(\mathrm{P}<0,0001)$ e sofreram redução de $0,153 \mathrm{mg} \mathrm{de} \mathrm{MS} / \mathrm{cm}^{3}$ $(\mathrm{DF} ; \mathrm{y}=-0,153 \mathrm{x}+4,014)$ e de $0,063 \mathrm{mg}$ de $\mathrm{MS} / \mathrm{cm}^{3}$ (DL; $y=-0,063 x+1,838)$, respectivamente para densidades de forragem e de lâminas foliares (também para cada $\mathrm{cm}$ acima de $4 \mathrm{~cm}$ de altura do pasto), o que pode estar relacionado ao efeito de diluição dos tecidos vegetais nos estratos superiores do pasto com o aumento da altura. Além desse efeito, outros fatores poderiam ter contribuído para esta resposta. Vários autores têm demonstrado que a taxa de surgimento de folhas tende a diminuir com o aumento da altura da planta, em decorrência do aumento do comprimento da bainha das folhas que se sucedem, o que acarretaria maior tamanho final das lâminas foliares, menor número de folhas por perfilho e menor perfilhamento (Lemaire \& Chapman, 1996; Nabinger, 1997; Duru \& Ducrocp, 2000). No entanto, esse aumento no tamanho parece estar mais associado ao aumento em comprimento da lâmina do que em sua largura, pelo menos em Paspalum notatum, pois, segundo Cruz et al. (2009), aumento no tamanho final das folhas não alterou o conteúdo de matéria seca ou sua área específica, o que pode ter reduzido a densidade volumétrica com o aumento da altura do pasto.

$\mathrm{Na}$ altura do pasto de $16 \mathrm{~cm}$, a massa seca de lâminas foliares foi menor $(\mathrm{P}=0,056)$ e a de material senescente maior $(\mathrm{P}=0,065)$ no estrato de 0 a $4 \mathrm{~cm}$ que nas demais alturas (Figura 1), o que comprova o efeito da altura do pasto na penetração da luminosidade no dossel. Segundo Hodgson (1990), a presença de material senescente nos estratos próximos ao solo deve-se ao sombreamento e à mobilização de nutrientes para as partes mais jovens da planta.

Tabela 1 - Características estruturais de pastagem nativa em diversas alturas de manejo

\begin{tabular}{|c|c|c|c|c|c|c|c|}
\hline \multirow[t]{2}{*}{ Característica } & \multicolumn{4}{|c|}{ Altura do pasto $(\mathrm{cm})$} & \multirow[t]{2}{*}{$\mathrm{R}^{2}$} & \multirow[t]{2}{*}{$\mathrm{T}$} & \multirow[t]{2}{*}{ Desvio-padrão } \\
\hline & 4 & 8 & 12 & 16 & & & \\
\hline Altura de entrada $(\mathrm{cm})$ & 4,8 & 8,5 & 12,2 & 15,7 & 0,99 & 0,001 & 0,44 \\
\hline Altura de saída (cm) & 4,7 & 8,1 & 11,9 & 15,2 & 0,97 & 0,009 & 0,63 \\
\hline Altura média real $(\mathrm{cm})$ & 4,7 & 8,3 & 12,0 & 15,4 & 0,95 & 0,002 & 0,55 \\
\hline Massa de forragem (kg de MS/ha) & 1360 & 2070 & 2500 & 2820 & 0,72 & 0,019 & 332,31 \\
\hline Massa de lâminas foliares (kg de MS/ha) & 632 & 1040 & 1284 & 1400 & 0,69 & 0,003 & 192,62 \\
\hline Densidade de forragem (mg de $\mathrm{MS} / \mathrm{cm}^{3}$ ) & 3,40 & 2,60 & 2,08 & 1,75 & 0,67 & 0,027 & 0,44 \\
\hline Densidade de lâminas foliares $\left(\mathrm{mg}\right.$ de $\left.\mathrm{MS} / \mathrm{cm}^{3}\right)$ & 1,58 & 1,30 & 1,07 & 0,87 & 0,57 & 0,011 & 0,22 \\
\hline Densidade de laminas foliares (estrato superior**) & 1,58 & 0,71 & 0,46 & 0,28 & 0,57 & 0,008 & 0,31 \\
\hline
\end{tabular}

${ }^{* *}$ Últimos $4 \mathrm{~cm}$ de altura do estrato. 
A fração colmo concentrou-se no estrato basal $(0 \mathrm{a} 4 \mathrm{~cm})$ em todas as alturas de manejo e praticamente foi inexistente nos demais estratos, caracterizando o hábito de crescimento prostrado das principais gramíneas do pasto (Boldrini, 1997), que concentram essas estruturas próxima ao solo. Considerando ainda que os colmos são estruturas de sustentação das folhas, a falta de colmos nos estratos superiores contribuiu para a redução na densidade de forragem (Figura 1).

Houve, a partir do segundo estrato (4 a $8 \mathrm{~cm}$ ), uma participação quase exclusiva de lâminas foliares, o que significa condições potenciais para a ingestão de forragem pelos animais, uma vez que os animais tendem a selecionar as folhas dos estratos superiores (Prache et al., 1998).

A altura do pasto teve correlação altamente significativa com a probabilidade de desfolhação ( $\mathrm{r}=-0,82$; $\mathrm{P}<0,0001)$, uma vez que a probabilidade de desfolhação reduziu com o aumento da altura, ou seja, com o aumento da altura do pasto, os animais pastejaram menos folhas em relação ao número total de folhas disponíveis. Essa relação está ligada à oferta de forragem instantânea (Figura 2), ou seja, mantendo-se o número de animais, conforme a massa de forragem aumenta, a probabilidade

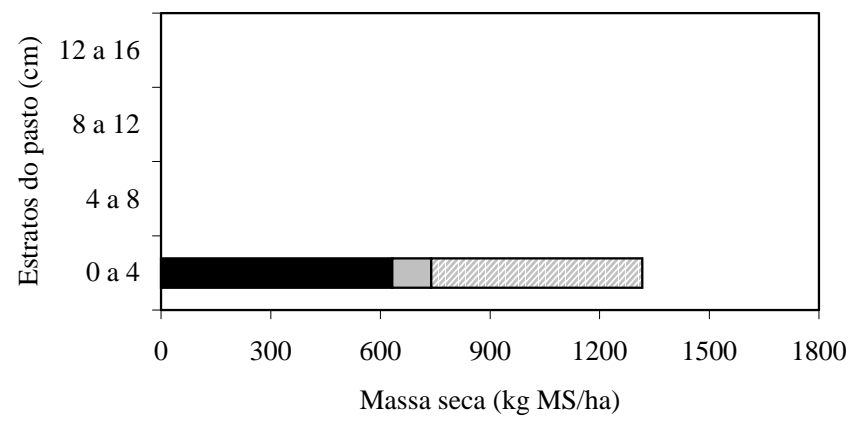

Lâminas $\square$ Colmos Material morto

$(4 \mathrm{~cm})$

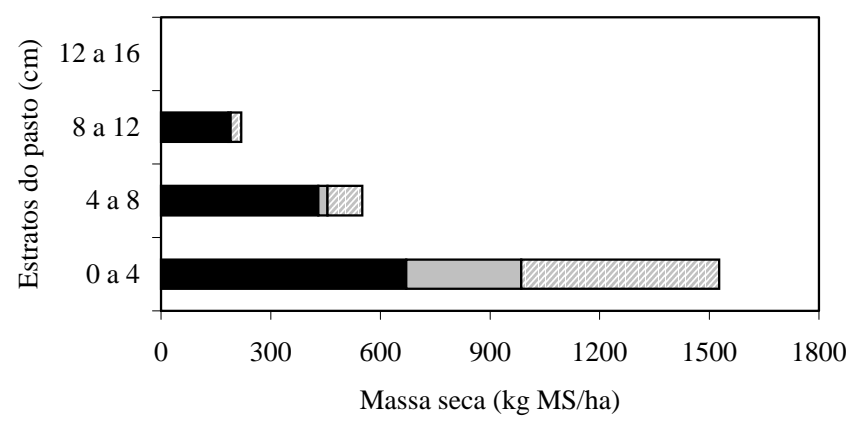

Lâminas $\square$ Colmos Material morto

$(12 \mathrm{~cm})$ de plantas ou folhas individuais serem pastejadas diminui. Pontes (2001), em pastagem de Lolium multiflorum, também encontrou maior probabilidade de desfolhação nas menores alturas avaliadas.

Os índices de seletividade passiva e ativa foram afetados negativamente pela altura do pasto $(r=-0,64$ e $r=-0,67$, respectivamente). O índice de seletividade passiva (Figura 3) não diferiu entre bezerras e ovelhas $(\mathrm{P}=0,233)$ e a equação geral de regressão comprovou que, após a altura do pasto de $6,7 \mathrm{~cm}$, a partir da qual os resultados foram inferiores ao valor de referência 1 , os animais selecionaram menos lâminas em expansão e as lâminas expandidas passaram a ser mais consumidas.

Esse resultado coincidiu com o ponto em que as folhas em expansão passaram a ser mais curtas que as expandidas (Figura 4), como conseqüência da menor disponibilidade e/ou facilidade de se encontrar folhas em expansão e da maior disponibilidade de folhas expandidas com o aumento da altura do pasto. No entanto, não significa que os animais deixaram de selecionar as lâminas em expansão, pois o índice de seletividade ativa permaneceu, em ambas as espécies animais, acima do valor de referência 1 (Figura 5). As ovelhas diferiram significativamente $(\mathrm{P}=0,0554)$ das

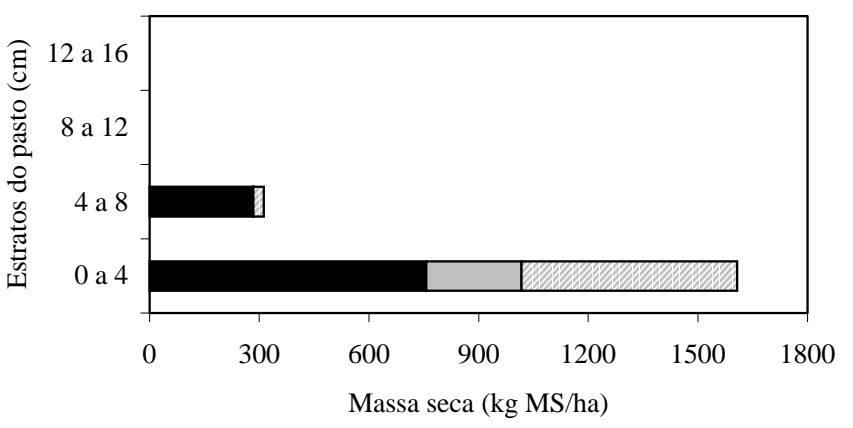

Lâminas $\square$ Colmos $\mathbb{Z}$ Material morto

$(8 \mathrm{~cm})$

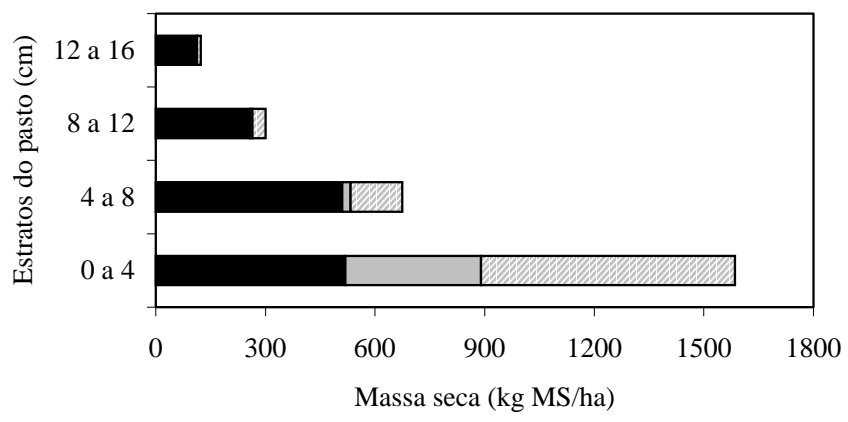

Lâminas $\square$ Colmos $\mathbb{Z}$ Material morto

$(16 \mathrm{~cm})$

Figura 1 - Massa seca de lâminas foliares, colmo e material morto (senescente) nos estratos do pasto em quatro alturas de manejo $(4,8,12,16 \mathrm{~cm})$. 


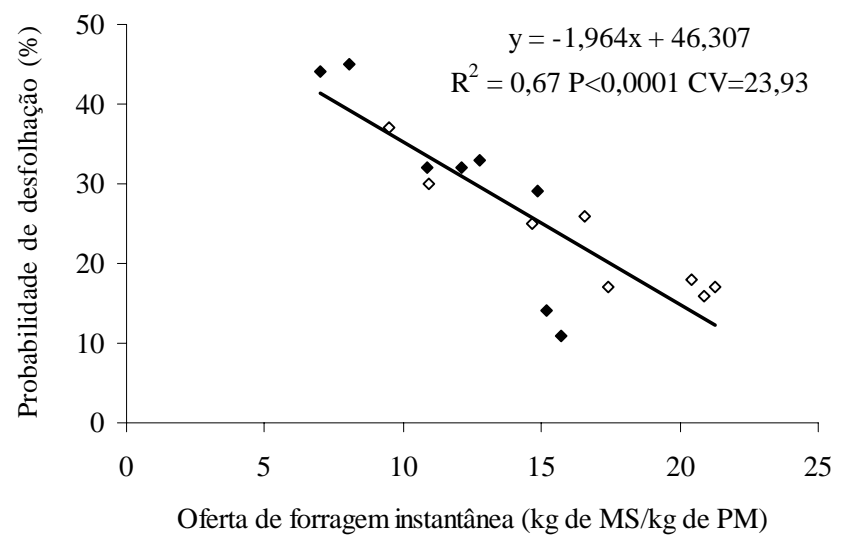

Figura 2 - Relação entre a oferta de forragem instantânea e a probabilidade de desfolhação do pasto por bezerras $(\diamond)$ e ovelhas $(\diamond)$ em quatro alturas de manejo $(4,8,12$ e $16 \mathrm{~cm})$.

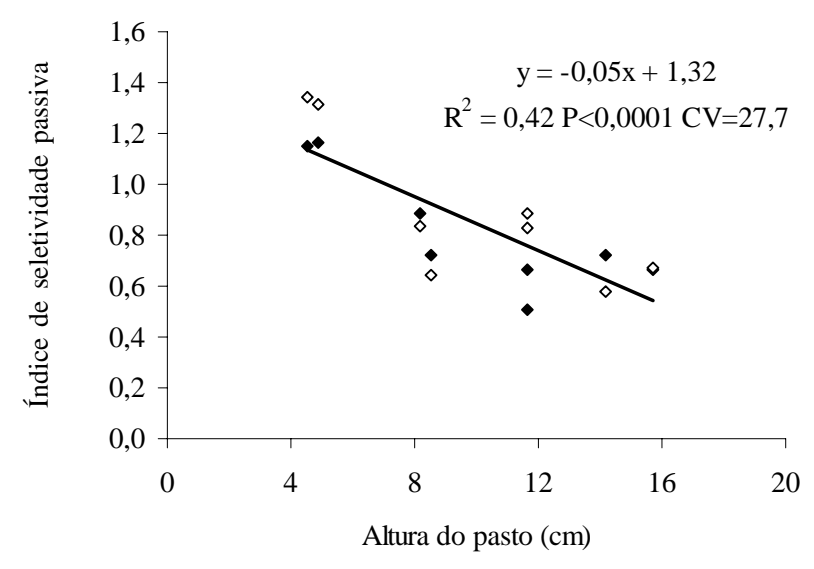

Figura 3 - Relação entre a altura do pasto e o índice de seletividade passiva do pasto, de bezerras $(\bullet)$ e ovelhas $(\diamond)$, em quatro alturas de manejo $(4,8,12,16 \mathrm{~cm})$.

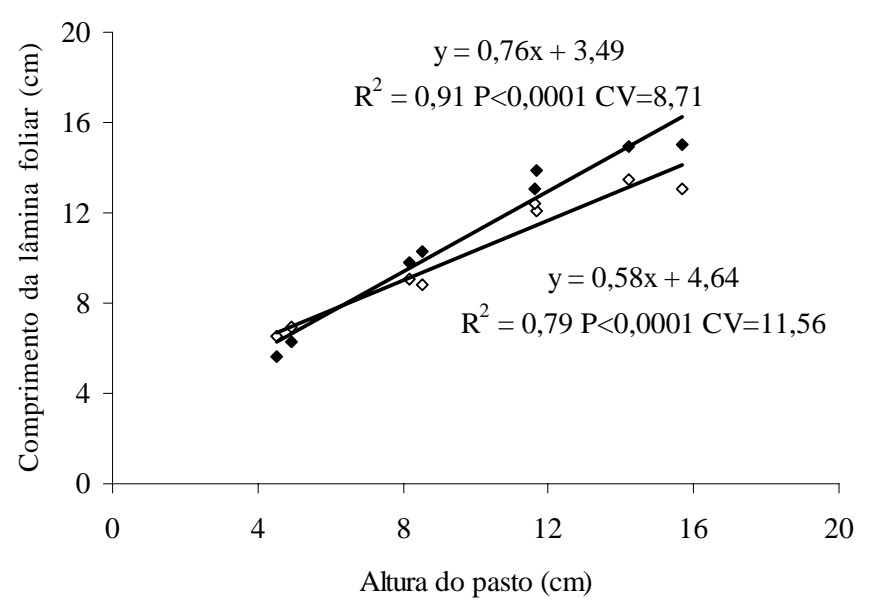

Figura 4 - Relação entre a altura do pasto e o comprimento de lâminas foliares expandidas $(\diamond)$ e em expansão $(\diamond)$ em pastagem natural em quatro alturas de manejo $(4,8,12,16 \mathrm{~cm})$.

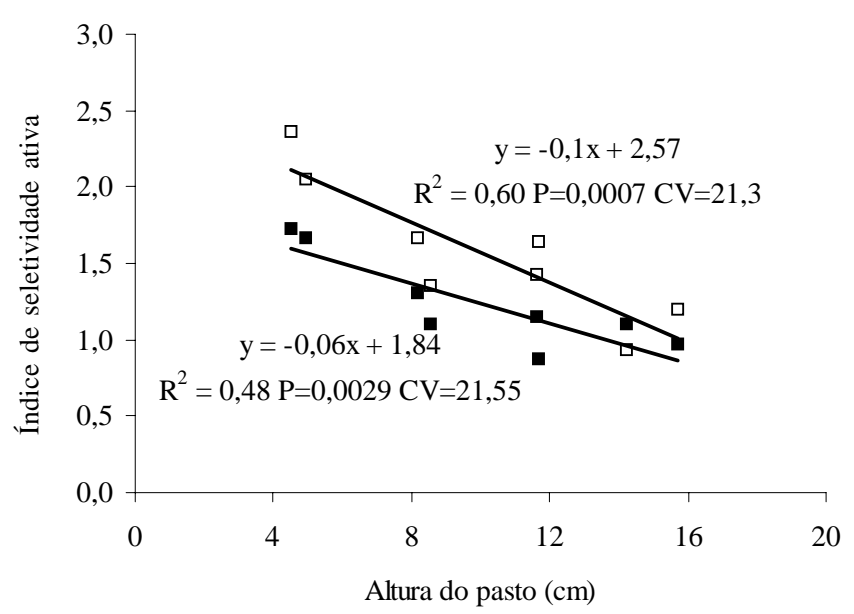

Figura 5 - Relação entre a altura do pasto e o índice de seletividade ativa do pasto por bezerras ( $\mathbf{\square})$ e ovelhas $(\square)$ em quatro alturas de manejo $(4,8,12,16 \mathrm{~cm})$.

bezerras quanto à intensidade de seletividade ativa, ou seja, foram mais seletivas no consumo de lâminas em expansão.

Silva (2004) encontrou alta preferência de novilhas em pastagem de capim-mombaça pelas folhas em expansão, preferência que tendeu a se estabilizar com o aumento na altura do pasto. Ainda segundo esse autor, a partir de certa altura do pasto, o tipo de lâmina foliar escolhida pareceu ter sido selecionado de maneira muito próxima da casual, mediada pela sua pronta acessibilidade.

Neste trabalho, houve maior consumo de folhas em expansão no manejo a $4 \mathrm{~cm}$ de altura, em virtude da maior facilidade de encontrá-las, fazendo com que ambos os índices de seletividades fossem maiores nesta altura do pasto. Isto não significa, no entanto, facilidade de apreensão da forragem, pois naquelas condições, a formação do bocado foi afetada pelo reduzido comprimento das lâminas foliares e nem o aumento na taxa de bocados seria capaz de compensar a reduzida massa de bocados dos animais (Gonçalves, 2007), o que se tornaria empecilho na produção animal.

\section{Conclusões}

A estrutura do campo nativo afeta o padrão de desfolhação e a oportunidade de pastejo de bezerras e ovelhas, pois o aumento da altura representa também menor facilidade de apreensão das lâminas foliares e dificulta a oportunidade de os animais encontrarem lâminas em expansão, em razão da menor densidade de lâminas foliares nos estratos superiores, porém os animais buscam sempre selecionar folhas mais jovens. Alturas do campo nativo extremamente baixas, embora apresentem distribuição de 
folhas com maior oportunidade de serem selecionadas, dificultam a formação do bocado dos animais em pastejo por seus reduzidos comprimentos.

\section{Literatura Citada}

AGUINAGA, A.A.Q.; CARVALHO, P.C.F.; ANGHINONI, I. et al. Produção de novilhos superprecoce em pastagem de aveia e azevém submetida a diferentes alturas de manejo. Revista Brasileira de Zootecnia, v.35, n.4, p.1765-1773, 2006.

ARNOLD, G.W. Grazing behaviour. In: SNAYDON, R.W. (Ed.) Managed grassland analytical studies. Amsterdam: Elsevier, 1987. p.129-135.

BARTHRAM, G.T. Experimental techniques: the HFRO sward stick. Penicuik, United Kingdom: Hill Farming Research Organization, 1985. p.29-30. (Biennial Report).

BOLDRINI, I.I. Campos do Rio Grande do Sul: caracterização fisionômica e problemática ocupacional. Porto Alegre: Instituto de Biociências, 1997. 56p. (Boletim).

BRAUN-BLANQUET, J. Fitosociologia: bases para el estudio de las comunidades vegetales. Madrid: H. Blume Ediciones, 1979. 820 p.

BRISKE, D.D.; RICHARDS, J. Plant responses to defoliation: a physiologic, morphologic and demographic evaluation. In: BEDUNAH, J.; SOSEBEE, R.E. (Eds.) Wildland plants physiological ecology and developmental morphology. Denver: Range Science Society, 1995. p.635-710.

CARVALHO, P.C.F.; MARÇAL, G.K.; RIBEIRO FILHO, H.M.N. et al. Pastagens altas podem limitar o consumo dos animais. In: REUNIÃO ANUAL DA SOCIEDADE BRASILEIRA DE ZOOTECNIA, 38., 2001, Piracicaba. Anais... Piracicaba: Sociedade Brasileira de Zootecnia, 2001. p.265-268.

CASTRO, C.R.C. Relações planta-animal em pastagem de milheto (Pennisetum americanum (L.) Leeke) manejadas em diferentes alturas com ovinos. 2002. 200f. Dissertação (Mestrado em Zootecnia) - Universidade Federal do Rio Grande do Sul, Porto Alegre, 2002.

CRUZ, P.; QUADROS, F.L.F;, THEAU, J.P. et al. Leaf traits as functional descriptors of the intensity of continuous grazing in native grasslands in the south of Brazil. Rangeland Ecology and Management, 2009. (no prelo).

DURU, M.; DUCROCP, H. Growth and senescence of the successive grass leaves on a tiller ontogenic development and effect of temperature. Annals of Botany, v.85, p.635-643, 2000.

EMPRESA BRASILEIRA DE PESQUISA AGROPECUÁRIA EMBRAPA. Sistema brasileiro de classificação de solos.
Rio de Janeiro: Centro Nacional de Pesquisa do Solo - CNPS, 1999. 412p.

GALLI, J.R.; CANGIANO, C.A.; FERNÁNDEZ, H.H. Comportamiento ingestivo y consumo de bovinos em pastoreo. Revista Argentina de Producción Animal, v.16, n.2, p.119-142, 1996.

GONÇALVES, E.N. Comportamento ingestivo de bovinos e ovinos em pastagem natural da Depressão Central do Rio Grande do Sul. 2007. 131f. Tese (Doutorado em Zootecnia) - Universidade Federal do Rio Grande do Sul, Porto Alegre, 2007.

HODGSON, J. Grazing management: science into practice. London: Longman Group, 1990. 200p.

LEMAIRE, G.; CHAPMAN, D. Tissue flows in grazed plants communities. In: HODGSON, J.; ILLIUS, A.W. (Eds.) The ecology and management of grazing systems. Wallingford: CAB International, 1996. p.3-36.

LEMAIRE, G.; AGNUSDEI, M. Leaf tissue turn-over and efficiency of herbage utilization. In: INTERNATIONAL SYMPOSIUM GRASSLAND ECOPHISIOLOGY AND GRAZING ECOLOGY, 1999, Curitiba. Proceedings... Curitiba: Universidade Federal do Paraná, 1999. p.165-196.

MARRIOT, C.; CARRÈRE, P. Structure and dynamics of grazed vegetation. Annales de Zootechnique, v.47, p.359-370, 1998.

NABINGER, C. Princípios da exploração intensiva de pastagens. In: SIMPOSIO SOBRE MANEJO DA PASTAGEM, 13., 1996, Piracicaba. Anais... Piracicaba: Fundação de Estudos Agrários Luiz de Queiroz, 1997. p.15-95.

OWEN-SMITH, N. The animal factor in veld management. In: TAINTON, N. (Ed.) Veld management in South Africa. Pietermaritzburg: University of Natal Press, 1999. p.117-138.

PENNING, P.D.; PARSONS, A.J.; NEWMAN, J.A. et al. The effects of group size on grazing time in sheep. Applied Animal Behaviour Science, v.37, p.101-109, 1993.

PONTES, L.S. Dinâmica do crescimento em pastagens de azevém anual (Lolium multiflorum) manejadas em diferentes alturas. 2001. 189f. Dissertação (Mestrado em Zootecnia) - Universidade Federal do Rio Grande do Sul, Porto Alegre, 2001.

PRACHE, S.; GORDON, I.J.; ROOK, A.J. Foraging behaviour and diet selection in domestic herbivores. Annales de Zootechnie, v.48, p.1-11, 1998

RIND, M.I.; PHILLIPS, C.J. The effect of group size on the ingestive and social behaviour of grazing dairy cows. Animal Science, v.68, p.589-596, 1999.

SILVA, A.L.P. Estrutura do dossel e o comportamento ingestivo de novilhas leiteiras em pastos de capim Mombaça. 2004. 104f. Tese (Doutorado em Agronomia) Universidade Federal do Paraná, Curitiba, 2004.

STATISTICAL ANALYSES SYSTEM - SAS. SAS/STAT user's guide: statistics. 4.ed. Version 6, 1996. 943p. 